\title{
Health systems efficiency in Eastern Mediterranean Region: a data envelopment analysis
}

\author{
Hamed Seddighi ${ }^{1}$ (10, Farhad Nosrati Nejad ${ }^{2^{*}}$ (1) and Mehdi Basakha ${ }^{2}$
}

\begin{abstract}
Background: One of the most important issues in public policy and welfare state is health care. Poor management leads to the waste of resources, including money, human resources, facilities, and equipment.

Aims: This paper seeks to answer the question of which eastern Mediterranean countries are more effective in allocating their health resources, and does Iran, in relation to those countries, have an effective health system.

Methods: This study examined technical efficiency among eastern Mediterranean countries in 2018. Data were extracted from Global Health Observatory data World Health Organization. We applied input-oriented Data Envelopment Analysis (DEA) models to estimate efficiency scores. Inputs are Physicians density per 10,000 populations, Total hospital beds per 10,000 populations, Current expenditure on health, \% of gross domestic product and outputs are infant survival rate and Life expectancy.

Results: The most efficient health systems in the eastern Mediterranean were Bahrain, Egypt, Iran, Lebanon, Morocco, Oman, Pakistan, Qatar, Tunisia and the United Arab Emirates. The inefficient countries are Iraq, Jordan, Kuwait, Libya, Palestine and Saudi Arabia.

Conclusions: Among the efficient countries, one category of high-entry countries such as Bahrain and Qatar with high input especially in health expenditure had higher output. The second group of countries with lower inputs such as Iran and Morocco has been able to produce similar output with other countries. Also, inefficiency in countries such as Saudi Arabia can be attributed to this with higher input such as health expenditure has lower output such life expectancy and infant survival rate.
\end{abstract}

Keywords: Efficiency, Resource allocation, Health care economics and organizations, Health services, Life expectancy

\section{Background}

The health sector is one of the most important service sectors and indicators of development [1]. Health systems today form one of the largest sectors of the world's economy [2]. It was found that when GDP increased, health expenditure in general increases [3]. The share of health expenditures in the budgets of low- and middle-income

*Correspondence: Farhad.nosrati@gmail.com

${ }^{2}$ Social Welfare Management Department, University of Social Welfare and Rehabilitation Sciences, Tehran, Iran

Full list of author information is available at the end of the article countries is increasing. Countries such as Brazil, Russia, India, China, and South Africa remain to be major drivers of such change since 1990s [4]. Getzen and Jakovljevic confirmed that shifts in GDP growth rates have already reflected heavily on world's health expenditure landscape [5]. Purchase power parity in terms of health expenditure in low and middle-income countries' has already grown in some indicators from almost $26.1 \%$ in 1995 to $39.7 \%$ in 2013, in only a span of 19 years [6]. Over the past few decades, national health spending has risen sharply around the world. It seems that the share of global medical spending by emerging economies is increasing and 
the share of rich countries is declining [7]. With the rapid growth in the costs of the health sector worldwide, economic experts, managers, and decision-makers are seeking to find new ways to limit costs and increase efficiency [8]. Despite the high volume of resources allocated to the health sector, there is a gap between the growth of the available resources and the resources needed by the health sector, which highlights the need for effective use of resources [9].

The World Health Organization (WHO) in its report emphasized on three goals for the health system [10] including improving health, meeting non-medical needs, and ensuring that financial burden is distributed equitably. In order to achieve this, the WHO has emphasized the performance of health systems [11]. Evaluating the effectiveness and efficiency of health systems is the measurement of the performance of system management. This comparison, when done in a large scale and in the health systems of the countries, shows the results of the selection of managers' policies and practices [10].

Poor management leads to the waste of resources, including money, manpower, buildings, and equipment. Such a loss means that a certain share of services (outputs) can be achieved with fewer resources. By preventing the loss of financial and human resources, they can be used to provide high-quality and cost-effective services [12]. Financial economic analysis provides a logical and specific framework for analyzing important issues in health care [13]. Deciding on the optimal provision of health care is a complex task and requires information about system performance for decision makers. The task of health economists is to analyze issues and report the results of economic assessments in a variety of ways to health policymakers [14]. In addition, with population aging, it is needed national strategies for sustainability of health systems. Countries whose populations are moving faster toward old age need to invest and spend more on health care for the elderly [15]. Non-communicable diseases will continue to be a challenge for low- and middle-income countries. High and out-of-pocket costs will impoverish 150 million people worldwide [16]. Despite significant global health gains, reports show that many low- and middle-income countries are not aligned with global health goals, and the gap between low-income and high-income countries seems unlikely to be narrowed. Current trends show that a significant increase in the resources of the health system requires coordinated action [17]. Poor countries are not able to provide enough funding to meet their health needs in the short to medium term. Governments in these countries have limited ability to collect taxes or health insurance benefits because people are poor and many people work in the informal sector, making it difficult to collect taxes [18].
This paper seeks to answer the question of which countries are more effective in allocating their health resources in Eastern Mediterranean Region, and does Iran, in relation to those countries, have an effective health system?

\section{Literature}

Productivity or efficiency is a criterion for measuring performance, and the value of the input (i.e., what is being used in production) is evaluated by the output (i.e., what is obtained) [19]. Efficiency is a very comprehensive concept, and it is discussed in various areas such as engineering, management, economics, and health. Therefore, different definitions of efficiency are provided in various sources. Farrell defines a firm's efficiency as "to produce an output to a sufficiently large extent than a given input value", and it specifies the technical allocation and economic performance of its types [20]. In many studies were used data envelopment analysis (DEA) method to investigate health systems efficiency [21-24].

It was reviewed 317 studies on health efficiency in a systematic review study, which were divided into two types of micro- and macro-level studies [25]. Micro-level studies evaluated the efficiency and function of health units such as hospitals and clinics [26]. Of course, some recent studies with a macro-level approach have also evaluated the performance of healthcare centers [27-31]. In most of these studies, the outcomes and impacts of the health system are measured in terms of life expectancy, and the main input in most studies is the per capita cost of health. In another study was used DEA method to investigate life expectancy and health expenditure evolution in eastern Europe [23].

It was found in a systematic review of 137 papers that most of reviewed studies employed data envelopment analysis for measuring efficiency in health systems [32]. In an another study was found that Lebanon, Qatar, and Morocco have the most efficient health systems in Middle east and North Africa (Mena) region [33]. Bousmah et al. $\mathrm{n}$ their paper analyzed health efficiency in 18 countries between 1995-2012 [34]. In a study about health efficiency in 18 countries between 1995-2012 was found that increasing health expenditure in the MENA region will not result health outcome improvement necessarily and full efficiency of health system [34].

Spinx and Halings [35] evaluated the effects of socioeconomic determinants on the outcome of health care. They used unemployment rate, the level of attribution, and GDP per capita as inputs. Ratzald Roberts et al. [36] provided a comprehensive model of inputs in which social environment, lifestyle, access to health services, and health costs were considered as inputs. Some studies also looked at hospital beds, the number of health care 
workers and health expenditure as inputs [30, 37]. In a study, two models with different inputs and the same output were studied. In the first model, the number of physicians and beds along with health expenditures were set as input, and in the second model, GDP per capita along with consumption of vegetables and fruits were specified as input. Outputs or outcomes in the health system were considered life expectancy and infant survival rate. By comparing these two models through the data envelopment analysis (DEA) method, the first model was found to be more appropriate [38].

\section{Methods}

In DEA models, the solution for improving inefficient units is to reach the efficiency boundary. The borderline consists of units of efficiency 1 . In general, there are two types of solutions for improving inefficient units and reaching the efficiency limit [39]: (A) Decrease inputs without reducing outputs until the unit reaches the border (this approach is referred to as the nature of performance improvement institutes or measures of input-oriented efficiency); (B) increasing outputs by reaching a unit on the efficiency boundary without attracting more inputs (this approach is referred to as the nature of performance improvement or output-oriented performance measurement).

In the DEA models with the input-oriented approach, it is sought to achieve a technical inefficiency ratio that should be reduced in inputs, so that the unit remains within the efficiency boundary without changing the output. However, in the output-driven viewpoint, it is tried to determine the ratio at which outputs should be increased so that the unit can reach the efficiency boundary without changing inputs.

All the Eastern Mediterranean countries base on world health organization, were considered as a decision-maker or decision-making unit (DMU) in the analysis. In term of homogeneity, Six countries, including Afghanistan, Djibouti, Somalia, Sudan, Syria and Yemen, were excluded from the analysis because of low income in compare to other countries [40]. Exclusion criteria is Gross domestic products (GDP), according to the World Bank. In the findings, the results are presented in two ways: BCC and CCR (Charnes, Cooper \& Rhodes model), and two inputcentered and outbound approach, but for analyzing and discussing the output-oriented approach, because the health system seeks to maximize health rather than keep resources and minimize inputs $[37,38]$.

In this study, as shown in Fig. 1, outcomes were considered to be life expectancy at birth and infant survival rate. These two outcomes were chosen based on previous studies, as in many studies they were two of the most commonly used outputs. The reason behind the use of infant survival rate rather than the rate of infant mortality is the nature of DEA which should have a positive outlet. The infant survival rate is obtained by the following formula [41]:

$$
\mathrm{ISR}=1-\mathrm{IMR} / 1000
$$

The input and output definitions are provided in Table 1. For analysis, the DEA online solver online application, available at the University of Hagen, Germany, was used. The research data were derived from World Health Organization's Health Surveillance Sect. 2017. All input data can be seen in Table 2.

\section{Results}

Average of life expectancy in the countries studied was 74.17; maximum was for Qatar with 78.2 and minimum was for Pakistan with 66.4, respectively. The average infant survival rate is around 92 in the region, with a maximum of 199 for Bahrain and a minimum of 16.86 for Pakistan. The average health expenditure in the region is \$ 695.3, with the highest being \$ 2106 and Pakistan's lowest at $\$ 36$. The average number of physicians is 17.9 per ten thousand; this rate is 31 for Lebanon and 6.3 for Morocco. The average of hospital beds in all public and private centers for all patients per 10,000 populations was 17.7.

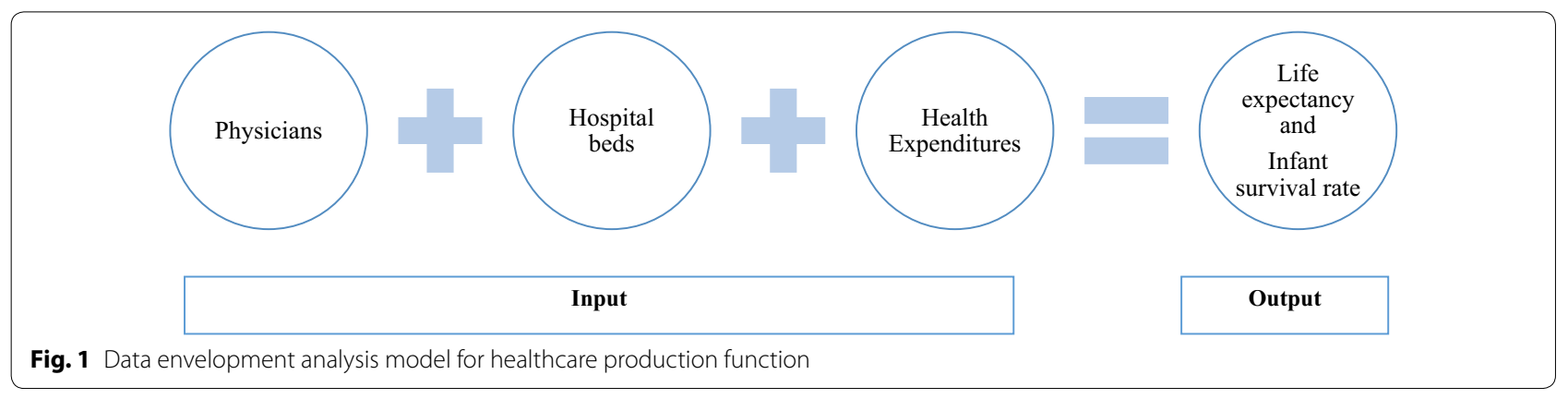


Table 1 Inputs and outputs definition of data envelopment analysis

\begin{tabular}{lll}
\hline Source & Parameter & Name \\
\hline OECD health data/WHO health observatory & $X_{1}$ & Physicians, density per 1000 population (head counts) \\
OECD health data/WHO health observatory & $X_{2}$ & Total hospital beds, per 1000 population \\
OECD health data/WHO health observatory & $X_{3}$ & Current expenditure on health, \% of gross domestic product \\
OECD health data/WHO health observatory & Y1 & Life expectancy \\
OECD health data/WHO health observatory & Y2 & Infant survival rate (calculated from infant mortality rate, deaths per \\
& & O O00 live births) \\
\hline
\end{tabular}

Table 2 Data entered into the software

\begin{tabular}{llllll}
\hline Country & Health expenditure & Physicians & Hospital beds & Infant survival rate & Life expectancy \\
\hline Bahrain & 1243 & 24.0 & 18.9 & 199 & 76.9 \\
Egypt & 178 & 8.1 & 14.3 & 49 & 73.2 \\
Iran & 351 & 11.4 & 17.0 & $75 / 92,308$ & 75.5 \\
Iraq & 8.4 & 13.0 & $36 / 03,704$ & 68.9 \\
Jordan & 292 & 14.1 & 14.0 & $65 / 66,667$ & 74.1 \\
Kuwait & 359 & 29.0 & 20.4 & $141 / 8571$ & 74.7 \\
Lebanon & 1386 & 31.0 & 27.3 & $141 / 8571$ & 74.9 \\
Libya & 569 & 19.5 & 37.0 & $89 / 90,909$ & 72.7 \\
Morocco & 372 & 6.3 & 11.0 & $40 / 66,667$ & 74.3 \\
Oman & 190 & 14.9 & 99 & 76.6 \\
Pakistan & 675 & 10.0 & 6.3 & $16 / 85,714$ & 66.4 \\
Palestine & 36 & 12.8 & $54 / 55,556$ & 73.5 \\
Qatar & 305 & 21.7 & 12.0 & $141 / 8571$ & 78.2 \\
Saudi Arabia & 2106 & 25.0 & 22.3 & $75 / 92,308$ & 74.5 \\
Tunisia & 1147 & 23.9 & 21.8 & $165 / 6667$ & 75.3 \\
United Arab Emirates & 13.0 & 13.6 & 77.1 \\
\hline
\end{tabular}

Table 3 Health system efficiency ranking

\begin{tabular}{llllll}
\hline Score & Countries & Rank & Score & Countries & Rank \\
\hline 1 & Tunis & 1 & 1 & Bahrain & 1 \\
1 & Emirate & 1 & 1 & Egypt & 1 \\
0.98 & Jordan & 2 & 1 & Iran & 1 \\
0.98 & Palestine & 2 & 1 & Lebanon & 1 \\
0.96 & Kuwait & 3 & 1 & Morocco & 1 \\
0.96 & Saudi Arabia & 3 & 1 & Oman & 1 \\
0.96 & Libya & 3 & 1 & Pakistan & 1 \\
0.91 & Iraq & 4 & 1 & Qatar & 1 \\
\hline
\end{tabular}

Based on Table 3 the most efficient health systems in the eastern Mediterranean were Bahrain, Egypt, Iran, Lebanon, Morocco, Oman, Pakistan, Qatar, Tunisia and the United Arab Emirates. The inefficient countries are Iraq, Jordan, Kuwait, Libya, Palestine and Saudi Arabia. If the countries are ranked in terms of efficiency, Jordan and Palestine come in second, followed by Kuwait, Saudi
Arabia and Libya, and Iraq fourth. The score of efficiency between countries varies from 1 to 0.91 . The efficiency scores are shown in Table 4.

\section{Discussion}

As stated in the introduction, performance enhancement is achieved in two forms [20]. In the first form, inputs are reduced without decreasing outputs until the unit reaches the boundary value (this is the nature of the institutions of performance improvement or performance measurement with the input-oriented nature of the system). In saving resources and reducing input, it must be taken not to reduce the quality of healthcare activities. Rather, the goal is to reduce input if possible while maintaining quality [42]. In the second form, outputs increase until it reaches one unit on the efficiency boundary without absorption of any further inputs (this approach is referred to as the nature of performance improvement performance or output-oriented output efficiency assessment) [20]. 
Table 4 Health system efficiency in studied countries using the data envelopment analysis method

\begin{tabular}{|c|c|c|c|}
\hline Inefficient country & Reference countries & Activity level & Inefficiency score \\
\hline \multirow[t]{3}{*}{ Iraq } & Iran & 0.329599 & 0.085384 \\
\hline & Morocco & 0.647993 & \\
\hline & Qatar & 0.022409 & \\
\hline \multirow[t]{4}{*}{ Jordan } & Iran & 0.353770 & 0.015488 \\
\hline & Morocco & 0.419751 & \\
\hline & Oman & 0.221950 & \\
\hline & Emirates & 0.004529 & \\
\hline \multirow[t]{3}{*}{ Kuwait } & Oman & 0.165197 & 0.035780 \\
\hline & Qatar & 0.323054 & \\
\hline & Emirates & 0.511750 & \\
\hline \multirow[t]{3}{*}{ Libya } & Bahrain & 0.045116 & 0.036242 \\
\hline & Lebanon & 0.093489 & \\
\hline & Tunisia & 0.861395 & \\
\hline \multirow[t]{3}{*}{ Palestine } & Iran & 0.186013 & 0.019409 \\
\hline & Morocco & 0.638622 & \\
\hline & Oman & 0.175365 & \\
\hline \multirow[t]{2}{*}{ Saudi Arabia } & Oman & 0.670161 & 0.035272 \\
\hline & Qatar & 0.329839 & \\
\hline
\end{tabular}

This study, according to the type of input and output and the model of health production, two methods can be interpreted. First, the effectiveness of the health system in countries through reduced inputs includes health expenditure, hospital beds and the number of physicians without a decrease in output, that is, infant survival rate and life expectancy at birth. Or an increase in outputs, including the infant survival rate and life expectancy at birth, without increasing health expenditures, the number of physicians and the number of hospital beds will increase efficiency. Considering that the DEA method evaluates each country according to the input and output of several decision-making units of the reference country, the countries that have demonstrated their full effectiveness, according to other countries studied in this research, with fewer or similar inputs had equal outputs. Thus, if in these analysis countries such as Iran and Pakistan achieved complete efficiency, they could be interpreted as having less relative inputs than other countries (e.g., health expenditures, hospital beds, and the number of physicians) and almost the same output in terms of healthy life expectancy and infant survival rate compared to the other countries. Obrizan et al. (2018) in a study on health expenditures and longevity indicated that that countries' health expenditure has inconsistent effects on life expectancy. Furthermore, the effects are larger for countries at the left margin of the longevity distribution, and higher health costs can have significant returns in countries with low-longevity [43].
Countries that are more inefficient like Kuwait and Saudi Arabia can be attributed to the have a much larger influx than other countries, which means either much more health expenditure per capita or per capita physician and hospital beds, or combining these three high rates, while in outputs, there was not much difference in terms of healthy life expectancy at birth and infant survival rate. For example, life expectancy in the Saudi Arabia was the same as that in Iran (74.5 years compared to 75 years), while its health expenditure per capita was more than three times as much as Iran, and thus, its health system has been shown to be inefficient in DEA compared to Iran. It was indicated that lifestyle, health behavioral health beliefs and shared culture are effective on healthcare system quality besides of the physicians' number and hospital beds [44]. Arab countries, more than other countries, spend public resources on education and health, but they do not have the appropriate output to investigate this inefficiency [45]. However, health status were influenced by health care expenditure through improving life expectancy at birth, reducing death and infant mortality rates in low-income countries such as countries in sub-Saharan Africa region [46]. Healthy life expectancy has more than doubled in the past 200 years, but in the past few decades its growth is not as high with the increase in life expectancy reaching over 70 years globally. This growth is much slower, especially in middle income and higher income countries, with an average of 81.4 years. Therefore, the growth of life expectancy at birth is not expected to be proportionate to the 
growth of health expenditure, hospital beds, physicians, and other health system inputs. Compared to the past, people have a longer and healthier life in the present age, but this achievement has cost a lot. Advances in treatment, as well as the introduction of new drugs, have also increased longevity [47]. Demand in the healthcare sector has increased significantly due to the spread of noncommunicable diseases, home care, and the high cost of treatment and care in the last years of life. However, technological innovations in medicine have not yet expanded sufficiently in terms of cost-effectiveness resource allocation [48]. Universal Health Coverage (UHC) is a comprehensive health system approach that facilitates a wide range of health services and significantly improves the life expectancy at birth and healthy life expectancy [49]. In addition, it is indicating that public health programs like sanitation and vaccination also affect life expectancy [49]. Even with rising health spending, low and middleincome countries need to coordinate between promoting public health, controlling non-communicable diseases, and improving population health, but this is currently a major challenge [50].

\section{Conclusion}

In this study, we evaluated the efficiency of health systems in eastern Mediterranean countries using the DEA method. The health system of Iran compared to the East Mediterranean countries was fully effective, indicating that in terms of life expectancy and infant survival rate (two very important health system indicators), Iran compared in proportion to its inputs (i.e., health expenditures, physicians' ratio, and hospital beds) is fairly well-suited. The efficiency of Iran's health system is mostly related to inputs than health outcomes. Also, this study showed increasing health expenditure and healthcare facilities will not guarantee better performance in healthcare. In some countries with weak output in life expectancy and infant survival rate, increasing output would be effective. However, in eastern Mediterranean countries, balance between inputs and outputs should consider for better allocating resources.

\section{Acknowledgements}

Not applicable.

\section{Authors' contributions}

HS: Conceptualization, Formal Analysis, Methodology, Software, Visualization, Writing —Original Draft Preparation. FN and MB: Conceptualization, Funding Acquisition, Methodology, Writing — Review \& Editing. All authors read and approved the final manuscript.

\section{Funding}

This project has received funding from the University of Social Welfare and Rehabilitation Sciences.

\section{Availability of data and materials}

The data supporting the findings in this study is publicly available at: https:// apps.who.int/gho/data/node.main

\section{Ethics approval and consent to participate}

Not applicable.

\section{Consent for publication}

Not applicable.

\section{Competing interests}

The authors declare that they have no competing interests.

\section{Author details}

1 Student Research Committee, University of Social Welfare and Rehabilitation Sciences, Tehran, Iran. ${ }^{2}$ Social Welfare Management Department, University of Social Welfare and Rehabilitation Sciences, Tehran, Iran.

Received: 13 April 2020 Accepted: 23 June 2020

Published online: 13 July 2020

\section{References}

1. Jakovljevic M, Timofeyev Y, Ranabhat C, et al. Real GDP growth rates and health care spending - Comparison between the G7 and the EM7 countries. Research Square. 2020. https://doi.org/10.21203/rs.2.19900/v1.

2. Chang AY, et al. Past, present, and future of global health financing: a review of development assistance, government, out-of-pocket, and other private spending on health for 195 countries, 1995-2050. Lancet. 2019;393(10187):2233-60

3. Ke X, Saksena P, Holly A. The determinants of health expenditure: a country-level panel data analysis. Geneva: World Health Organization; 2011. p. 26.

4. Jakovljevic M, et al. Evolving health expenditure landscape of the BRICS nations and projections to 2025. Health Econ. 2017;26(7):844-52.

5. Jakovljevic M, Getzen TE. Growth of global health spending share in low and middle income countries. Front Pharmacol. 2016;7:21.

6. Jakovljevic M, et al. Cost-effectiveness and resource allocation (CERA) 18 years of evolution: maturity of adulthood and promise beyond tomorrow. Cost Eff Resour Alloc. 2020;18(1):15.

7. Jakovljevic MM. Comparison of historical medical spending patterns among the BRICS and G7. J Med Econ. 2016;19(1):70-6.

8. Issel LM, Wells R. Health program planning and evaluation. US: Jones \& Bartlett Learning; 2017.

9. Atun $\mathrm{R}$, et al. Health-system reform and universal health coverage in Latin America. Lancet. 2015;385(9974):1230-47.

10. World Health Organization. World health statistics 2016: monitoring health for the SDGs sustainable development goals. Switzerland: World Health Organization; 2016.

11. Seddighi H, Salmani I. Online volunteering, a way to reduce health inequalities: a review study. J Comm Health Res. 2018;7(4):256-64.

12. Vlădescu C, et al. Romania: health system review. Health Syst Transit. 2016;18(4):1-170.

13. Seddighi H, Morovvati A. Efficiency evaluation of road relief bases of Yazd province red crescent society in new year plan. J Rescue Relief. 2013;5(3):18-26.

14. Chevreul K, et al. France: health system review 2015. Health Systems Trans. 2015;17(3):1-218.

15. Jakovljevic M, Laaser U. Population aging from 1950 to 2010 in seventeen transitional countries in the wider region of South Eastern Europe. SEEJPH. 2015;2015:3.

16. Jakovljevic $\mathrm{M}$, et al. Comparative financing analysis and political economy of noncommunicable diseases. J Med Econ. 2019;22(8):722-7.

17. Dieleman JL, et al. National spending on health by source for 184 countries between 2013 and 2040. Lancet. 2016;387(10037):2521-35.

18. Xu K, et al. Protecting households from catastrophic health spending. Health Aff. 2007:26(4):972-83.

19. Afonso A, St Aubyn M., Assessing health efficiency across countries with a two-step and bootstrap analysis. Appl Econ Lett. 2011;18(15):1427-30. 
20. Farrell M, PEARsoN E. Series A (General). J R Stat Soc B. 1957;120(3):253-32929.

21. Carrillo M, Jorge JM. DEA-like efficiency ranking of regional health systems in Spain. Soc Indic Res. 2017;133(3):1133-49.

22. Dincă G, Dincă MS, Andronic ML. The efficiency of the healthcare systems in EU countries - a DEA analysis. Acta Oeconomica. 2020;70(1):19-36.

23. Jakovljevic MB, Vukovic M, Fontanesi J. Life expectancy and health expenditure evolution in Eastern Europe — DiD and DEA analysis. Expert Rev Pharmacoecon Outcomes Res. 2016:16(4):537-46.

24. Önen Z, Sayın S. Evaluating healthcare system efficiency of OECD countries: A DEA-based study, in Operations research applications in health care management. Cham: Springer; 2018. p. 141-158.

25. Hollingsworth B. The measurement of efficiency and productivity of health care delivery. Health Econ. 2008;17(10):1107-28.

26. Moran $V$, Jacobs R. An international comparison of efficiency of inpatient mental health care systems. Health Policy. 2013;112(1-2):88-99.

27. Simar L, Wilson PW. Sensitivity analysis of efficiency scores: How to bootstrap in nonparametric frontier models. Manage Sci. 1998;44(1):49-61.

28. Smith P. Model misspecification in data envelopment analysis. Ann Oper Res. 1997;73:233-52.

29. Street A. How much confidence should we place in efficiency estimates? Health Econ. 2003;12(11):895-907.

30. Tajnikar M, Došenović Bonča P. Differences between health care systems and the single European health care market. J Bus Econ. 2007:25(2):309-24.

31. Von Elm E, et al. The strengthening the reporting of observational studies in epidemiology (STROBE) statement: guidelines for reporting observational studies. PLoS Med. 2007;4(10):e296.

32. Hafidz F, Ensor T, Tubeuf S. Efficiency measurement in health facilities: A systematic review in low-and middle-income countries. Appl Health Econ Health Policy. 2018;16(4):465-80.

33. Hamidi S, Akinci F. Measuring efficiency of health Systems of the Middle East and North Africa (MENA) region using stochastic frontier analysis. Appl Health Econ Health Policy. 2016;14(3):337-47.

34. Ventelou B, Abu-Zaineh M. Medicine and democracy: The importance of institutional quality in the relationship between health expenditure and health outcomes in the MENA region. Health Policy. 2016;120(8):928-35

35. Spinks J, Hollingsworth B. Cross-country comparisons of technical efficiency of health production: a demonstration of pitfalls. Appl Econ. 2009;41(4):417-27.

36. Retzlaff-Roberts D, Chang CF, Rubin RM. Technical efficiency in the use of health care resources: a comparison of OECD countries. Health Policy. 2004;69(1):55-72.
37. Varabyova Y, Schreyögg J. International comparisons of the technical efficiency of the hospital sector: panel data analysis of OECD countries using parametric and non-parametric approaches. Health Policy. 2013;112(1-2):70-9

38. Hadad S, Hadad Y, Simon-Tuval T. Determinants of healthcare system's efficiency in OECD countries. Eur J Health Econ. 2013;14(2):253-65.

39. Jeremic $V$, et al. An evaluation of European countries' health systems through distance based analysis. Hippokratia. 2012;16(2):170.

40. Lange GM, Wodon Q, Carey K, editors. The changing wealth of nations 2018: building a sustainable future. Washington, DC, USA: The World Bank; 2018.

41. Kumbhakar SC. Efficiency and productivity of world health systems: where does your country stand? Appl Econ. 2010;42(13):1641-59.

42. Jakovljevic M, et al. Do Health Reforms Impact Cost Consciousness of Health Care Professionals? Results from a Nation-Wide Survey in the Balkans. Balkan Med J. 2016:33(1):8-17.

43. Obrizan M, Wehby GL. Health expenditures and global inequalities in longevity. World Dev. 2018;101:28-36.

44. Grima S, et al. High out-of-pocket health spending in countries with a mediterranean connection. Front Public Healt. 2018:6:145.

45. Shafik N. Big spending, small returns: the paradox of human resource development in the Middle East. Cairo, Egypt: Egyptian Center for Economic Studies; 1996

46. Novignon J, Olakojo SA, Nonvignon J. The effects of public and private health care expenditure on health status in sub-Saharan Africa: new evidence from panel data analysis. Health Econ Rev. 2012;2(1):22.

47. Jakovljevic MB, Milovanovic O. Growing burden of non-communicable diseases in the emerging health markets: the case of BRICS. Front Public Health. 2015:3:65.

48. Jakovljevic M, et al. Underlying differences in health spending within the World Health Organisation Europe Region-comparing EU15, EU post2004, CIS, EU candidate, and CARINFONET countries. Int J Environ Res Public Health. 2019;16(17):3043.

49. Ranabhat $\mathrm{CL}$, et al. The influence of universal health coverage on life expectancy at birth (LEAB) and healthy life expectancy (HALE): a multicountry cross-sectional study. Front Pharmacol. 2018;9:960.

50. Jakovljevic M, et al. The impact of health expenditures on public health in BRICS nations. J Sport Health Sci. 2019;8(6):516.

\section{Publisher's Note}

Springer Nature remains neutral with regard to jurisdictional claims in published maps and institutional affiliations.
Ready to submit your research? Choose BMC and benefit from:

- fast, convenient online submission

- thorough peer review by experienced researchers in your field

- rapid publication on acceptance

- support for research data, including large and complex data types

- gold Open Access which fosters wider collaboration and increased citations

- maximum visibility for your research: over 100M website views per year

At $B M C$, research is always in progress.

Learn more biomedcentral.com/submissions 